\title{
Psychometric properties of the Swedish version of the satisfaction with life scale in a sample of individuals with mental illness
}

\author{
Danilo Garcia ${ }^{\text {Corresp., 1, 2, 3, 4, 5 }}$, Ali Al Nima ${ }^{3,4,5}$, Maryam Kazemitabar ${ }^{6,7}$, Clara Amato $^{5,8}$, Franco Lucchese $^{8,9}$, Marko \\ Mihailovic $^{10,11}$, Nobuhiko Kijima ${ }^{12,13}$ \\ ${ }^{1}$ Department of Behavioral Sciences and Learning, Linköping University, Linköping, Sweden \\ 2 Centre for Ethics, Law and Mental Health (CELAM), University of Gothenburg, Gothenburg, Sweden \\ 3 Department of Psychology, University of Gothenburg, Gothenburg, Sweden \\ 4 Promotion of Health and Innovation (PHI) Lab, Network for Well-Being, Karlskrona, Sweden \\ 5 Blekinge Centre of Competence, Region Blekinge, Karlskrona, Sweden \\ 6 Department of Psychology, University of Tehran, Tehran, Iran \\ 7 Promotion of Health and Innovation (PHI) Lab, Network for Well-Being, Tehran, Iran \\ 8 Promotion of Health and Innovation (PHI) Lab, Network for Well-Being, Rome, Italy \\ 9 Department of Dynamic and Clinical Psychology, University of Rome "La Sapienza", Rome, Italy \\ 10 Department of Psychiatry and Behavioral Sciences, Northwestern University, Chicago, United States \\ 11 Promotion of Health and Innovation (PHI) Lab, Network for Well-Being, Chicago, United States \\ 12 Promotion of Health and Innovation (PHI) Lab, Network for Well-Being, Tokyo, Japan \\ 13 Faculty of Business and Commerce, Keio University, Tokyo, Japan \\ Corresponding Author: Danilo Garcia \\ Email address: danilo.garcia@icloud.com
}

Background: Health assessment among individuals with mental health problems often involves measures of ill-being (e.g., anxiety, depression). Health is, however, defined as a state of physical, mental and social well-being and not merely the absence of disease (WHO, 1948, 2001). Hence, in order to address mental illness during the $21^{\text {st }}$ century, we need to develop methods for the prevention, identification and treatment of mental illness; but also, for the promotion, identification, and maintenance of well-being. In this context, over three decades of subjective well-being research have resulted in the development of measures of positive aspects of human life, such as, the Satisfaction with Life Scale (Diener et al., 1985). Our aim was to investigate the psychometric properties of the Satisfaction with Life Scale in a Swedish population of individuals with mental illness using both Classical Test Theory (CTT) and Item Response Theory (IRT).

Method: A total of 264 participants (age mean $=43.46, S D=13.31$ ) diagnosed with different types of mental illness answered to the Swedish version of the Satisfaction with Life Scale (five items, 7-point scale: 1 = strongly disagree, 7 = strongly agree)

Results: We found positive and significant relationships between the five items of the scale ( $r$ ranging from .37 to .75$)$, good reliability (Cronbach's alpha $=.86$ ), and that the one-factor solution had best goodness of fit (loadings between.52-.88, $p<.001$ ). Additionally, there were no significant differences in comparative fit indexes regarding gender and occupation status. All items had high discrimination values (between 1.95-3.81), but item 5 ("If I could live my life over, I would change almost nothing"); which had a moderate discrimination value $(1,7)$ and the highest estimated difficulty on response 7 (3.06). 
Moreover, item 2 ("The conditions of my life are excellent") had less discrimination and redundant difficulty with both item 1 ("In most ways my life is close to my ideal"; 2.03 ) on response 7 and with item 3 ("I am satisfied with my life"; -1.21) on response 1 . The five items together provided good information, with especial good reliability and small standard error within -1.00 up to about 2.00 and the highest amount of test information at 0.00 of the level of life satisfaction within this population.

Conclusions: Consistent with previous research, the scale had good reliability and provided good information across most of the latent trait range. In addition, within this population, sociodemographic factors such as gender and occupation status do not influence how individuals respond to the items in the scale. However, the items couldn't measure extreme levels of low/high life satisfaction. We suggest replication of these findings, the test of additional items, and the modification of items 2 and 5 in order to use the scale among individuals with mental illness. 
1 Submitted to PeerJ

2 Please do not quote or cite without permission

3

4 5

6 Danilo Garcia ${ }^{1-5 *}$, Ali Al Nima ${ }^{3,4,5}$, Maryam Kazemitabar ${ }^{6,7}$, Clara Amato 5,8 , Franco Lucchese 7

\section{Psychometric Properties of the Swedish Version of the Satisfaction with Life Scale in a} Sample of Individuals with Mental Illness 8, 9 , Marko Mihailovic ${ }^{10,11}$, Nobuhiko Kijima ${ }^{12,13}$

${ }^{1}$ Department of Behavioral Sciences and Learning, Linköping University, Linköping, Sweden ${ }^{2}$ Centre for Ethics, Law and Mental Health (CELAM), University of Gothenburg, Gothenburg, Sweden

${ }^{3}$ Department of Psychology, University of Gothenburg, Gothenburg, Sweden ${ }^{4}$ Promotion of Health and Innovation (PHI) Lab, Network for Well-Being, Karlskrona, Sweden ${ }^{5}$ Blekinge Centre of Competence, Region Blekinge, Karlskrona, Sweden ${ }^{6}$ Department of Psychology, University of Tehran, Tehran, Iran ${ }^{7}$ Promotion of Health and Innovation (PHI) Lab, Network for Well-Being, Tehran, Iran ${ }^{8}$ Promotion of Health and Innovation (PHI) Lab, Network for Well-Being, Rome, Italy ${ }^{9}$ Department of Dynamic and Clinical Psychology, University of Rome "La Sapienza”, Rome, Italy

${ }^{10}$ Department of Psychiatry and Behavioral Sciences, Northwestern University, Chicago, United States ${ }^{11}$ Promotion of Health and Innovation (PHI) Lab, Network for Well-Being, Chicago, United States

${ }^{12}$ Faculty of Business and Commerce, Keio University, Tokyo, Japan 
25

26

27

28

29

30

31

32

33

34

35

36

37

38

39

40

41

42

43

44

45

46

47

48

49

50

51

52

53

54

55

56

57

58

59

60

61

62

63

\begin{abstract}
Background: Health assessment among individuals with mental health problems often involves measures of ill-being (e.g., anxiety, depression). Health is, however, defined as a state of physical, mental and social well-being and not merely the absence of disease (WHO, 1948, 2001). Hence, in order to address mental illness during the $21^{\text {st }}$ century, we need to develop methods for the prevention, identification and treatment of mental illness; but also, for the promotion, identification, and maintenance of well-being. In this context, over three decades of subjective well-being research have resulted in the development of measures of positive aspects of human life, such as, the Satisfaction with Life Scale (Diener et al., 1985). Our aim was to investigate the psychometric properties of the Satisfaction with Life Scale in a Swedish population of individuals with mental illness using both Classical Test Theory (CTT) and Item Response Theory (IRT).
\end{abstract}

Method: A total of 264 participants (age mean $=43.46, S D=13.31$ ) diagnosed with different types of mental illness answered to the Swedish version of the Satisfaction with Life Scale (five items, 7-point scale: 1 = strongly disagree, 7 = strongly agree).

Results: We found positive and significant relationships between the five items of the scale $(r$ ranging from .37 to .75 ), good reliability (Cronbach's alpha $=.86)$, and that the one-factor solution had best goodness of fit (loadings between .52-.88, $p<.001$ ). Additionally, there were no significant differences in comparative fit indexes regarding gender and occupation status. All items had high discrimination values (between 1.95-3.81), but item 5 ("If I could live my life over, I would change almost nothing"); which had a moderate discrimination value (1.17) and the highest estimated difficulty on response 7 (3.06). Moreover, item 2 ("The conditions of my life are excellent") had less discrimination and redundant difficulty with both item 1 ("In most ways my life is close to my ideal"; 2.03) on response 7 and with item 3 ("I am satisfied with my life"; -1.21) on response 1 . The five items together provided good information, with especial good reliability and small standard error within -1.00 up to about 2.00 and the highest amount of test information at 0.00 of the level of life satisfaction within this population.

Conclusions: Consistent with previous research, the scale had good reliability and provided good information across most of the latent trait range. In addition, within this population, sociodemographic factors such as gender and occupation status do not influence how individuals respond to the items in the scale. However, the items couldn't measure extreme levels of low/high life satisfaction. We suggest replication of these findings, the test of additional items, and the modification of items 2 and 5 in order to use the scale among individuals with mental illness.

Keywords: Classical Test Theory; Item Response Theory; Life Satisfaction; Satisfaction with Life Scale; Mental Illness.

Peer] reviewing PDF | (2021:01:57362:1:0:NEW 26 Mar 2021) 
65 About half of the proportion of people on sick leave in Sweden are due to mental illness. This trend has been steadily increasing for the past 10 years (Swedish Social Insurance Agency, 2019). The term mental illness has been, however, difficult to define. One part of the definition encompasses the fact that about $90 \%$ of those who receive this diagnosis have one or more common mental disorders (Vingård, 2020). Common mental disorders include depression, general anxiety disorder, panic disorder, post-traumatic stress disorder, some phobic disorders, and obsessive-compulsive disorder. Indeed, among individuals with mental health problems, health assessment often involves measures of ill-being (e.g., anxiety, depression, stress). Health is, however, defined as a state of physical, mental and social well-being and not merely the absence of disease (WHO, 1948; 2001). Hence, in order to address mental illness during the $21^{\text {st }}$ century, one of the challenges is to develop methods for the prevention, identification and treatment of mental illness; but also, for the promotion, identification, and maintenance of well-being (Garcia, Nima, Granjard \& Cloninger, 2021).

Fortunately, over three decades of well-being research have resulted in the development of measures of positive aspects of human life, such as, subjective well-being (e.g., Diener, 1984, 2000; Diener, Lucas \& Oishi, 2018; Diener, Wirtz, Tov, Kim-Prieto, Choi, Oishi \& Biswas-Diener, 2010). Since these measures are mostly self-reports, a cornerstone in their implementation is the testing of their psychometric properties in different populations (Pavot, 2018). One of the most 83 prominent and commonly used instruments to operationalize the cognitive component of 84 subjective well-being, the Satisfaction with Life Scale, measures people's evaluations of life as a whole in relation to a psychological self-imposed ideal (Diener, Emmons, Larsen \& Griffin, 1985;

86 Pavot \& Diener, 1993; Pavot \& Diener, 2008; Pavot, Diener, Colvin \& Sandvik, 1991). The 
87 psychometric properties of the Satisfaction with Life Scale have been validated in different 88 populations, mostly using Classical Test Theory (CTT) (Chinni \& Hubley, 2014; Emerson, Guhn 89 \& Gadermann, 2017; Nima, Cloninger, Lucchese, Sikström \& Garcia, 2020a). Nevertheless, 90 despite the usefulness of common CTT techniques, the results are dependent on the characteristics 91 of the sample and the scale, thus, current research needs to address the psychometric properties of 92 the Satisfaction with Life Scale using complementary methods, such as, Item Response Theory 93 (IRT; Oishi, 2006, 2007; Nima, Cloninger, Persson, Sikström \& Garcia, 2020b). More specifically, changes in the characteristics of the sample (e.g., sample size, gender, and other sociodemographic factors) might have a significant effect on the psychometric properties of the measure at both item and scale levels (Oishi, 2007, 2006). For instance, individuals with mental illness do not only differ from the general population with regard to sociodemographic factors, such as, employment (Marwaha, Jonson, Bebbington, Angermeyer, Brugha, Azorin, Kilian, Hansen \& Toumi, 2007), (un)employment varies within this population (Granjard, Mihailovic, Amato, Kazemitabar, Lucchese, Jacobsson, Kijima \& Garcia, 2021). Additionally, CTT methodology does not provide researchers with sufficient information at different points along the scales' continuum (e.g., ranging from extremely satisfied with life to extremely unsatisfied with life), because in CTT the scale is assumed to have equal measurement problems or capacity at all points of the scales' continuum (Oishi, 2007). However, some items might be of varying weigh in relation to a person's life satisfaction and therefore influence the participant's actual score in life satisfaction in different ways (Oishi, 2007). IRT methods, in contrast, provide information about how each item helps to identify individuals with different levels of life satisfaction and also at which specific levels within the specific item this identification can be measured (Oishi, 2007). In other words, IRT methods depend basically on the assumption that 
110 individuals are independent of one another and that items behave in the same way for all

111 individuals, which means that the precision of location estimates pertain, besides the group's level

112 of life satisfaction, the individual's own level as well. This is in contrast to CTT, where the person's

113 test score is dependent on the items of the specific test and where the items' properties (e.g.,

114 difficulty and discrimination) in turn, are dependent on the characteristics of the sample. Hence,

115 IRT methods are sample and test independent (Oishi, 2007; see also Kijima, Takahashi, Noguchi

$116 \&$ Wantaanbe, 1998).

117 With regard to the Satisfaction with Life Scale, CTT studies have replicated the single

118 factor structure of the scale in different populations (Chinni \& Hubley, 2014; Emerson, Guhn \&

119 Gadermann, 2017). Nevertheless, both CTT and the few studies using IRT methodology show that

120 item 5 ("If I could live my life over, I would change almost nothing") is less accurate for the

121 measurement of life satisfaction compared to the other four (Pavot \& Diener, 2008; Oishi, 2006,

122 2007; Vittersø, Biswas-Diener, \& Diener, 2005; Nima, Cloninger, Persson, Sikström \& Garcia,

123 2020ab; for the same results among individuals with mental illness, see Jovanovic, Lazic \&

124 Gavrilov-Jerkovic, 2020). This specific item represents an evaluation over one's past life, thus, it

125 has been suggested that it probably requires respondents to make more of a global recollection

126 compared to, for example, item 2 (e.g., "The conditions of my life are excellent"), which rather

127 requires the apprehension of one's present life (Pavot \& Diener, 2008). That being said, since

128 responses to item 5 are significantly correlated with the responses to the other four items,

129 researchers are usually recommended to keep it in the scale (Pavot \& Diener, 2008). That being

130 said, as accurately suggested by Jovanovic and colleagues (2020), individuals with mental illness

131 have memory issues regarding the past (e.g., negativity bias), thus, such temporal-related problems

132 with specific items need to be scrutinized using IRT among populations with mental illness. 
133 In sum, when researchers validate subjective well-being measures, many of the

134 disadvantages of CTT and the advantages of IRT have been neglected (Oishi, 2007). In addition,

135 while many studies have used the Satisfaction with Life Scale to measure subjective well-being

136 among individuals with mental illness (e.g., Meyer, Rumpf, Hapke, \& John, 2004), only a few

137 studies have addressed the psychometric properties of the scale in this population (e.g., Arrindell,

138 Meeuwesen \& Huyse, 1991; Jovanovic, Lazic \& Gavrilov-Jerkovic, 2020). Therefore, in order to

139 propose this scale as a possible measure of subjective well-being among individuals with mental

140 illness, our aim was to investigate the psychometric properties of the Satisfaction with Life Scale

141 in a Swedish population of individuals with mental illness using both CTT and IRT. More

142 specifically, we tested the expected positive significant intercorrelations between the five items in

143 the scale (1); we explored (2) and confirmed (3) the expected single factor structure of life

144 satisfaction; we tested if the scale measured life satisfaction equally across both gender and

145 occupation status groups (4); and finally, we tested the five items' information characteristics using

146 IRT (5). See Table 1 for the Swedish version of the scale.

Table 1 about here

\section{Method}

\section{Ethical Statement}

150 The study was approved by the Swedish Ethical Review Authority (Dnr. 2017/305) and conducted

151 in accordance with the ethical standards of the 1964 Helsinki declaration and further amendments.

152 Hence, all participants were provided with the necessary information to obtain verbal consent (e.g.,

153 aims of the study, that participation was anonymous and voluntary).

\section{Participants and Procedure}


155 The data used here has been previously published elsewhere (Granjard, Mihailovic, Amato,

156 Kazemitabar, Lucchese, Jacobsson, Kijima \& Garcia, 2021), but it has never been analyzed as in

157 the present study. All individuals with mental illness between 18-65 years of age who received

158 support in each of the five municipalities in Blekinge were contacted $(N=621)$. The support

159 includes: help with everyday finances, help with daily shores, transport, support when contacting

160 authorities, help taking social contact, support seeking job or occupation, and help with lifestyle

161 habits (https://sweden.se/society/swedens-disability-policy/). The survey was conducted at the

162 outpatient clinics. The staff working closest to the clients were responsible for the exclusion

163 procedure. A total of 146 individuals were excluded due to severe dementia or substance use

164 disorder at the time the data was collected. Another 62 individuals declined to participate in the

165 study and 126 individuals did not respond to the survey questions (i.e., a total 188 individuals who

166 dropped out). Thus, the final sample represented roughly $60 \%$ of those eligible to participate $(n=$

167 475): 287 individuals (148 males, 134 females, and 5 missing) with a mean age of 43.46 years (SD

$168=13.32$ ). Of these 287 individuals, $67 \%$ reported doing it without any help, $24 \%$ with some help,

169 and 9\% did not answered to this question. Regarding education, about $3.5 \%$ of the respondents did

170 not finish primary school, $23.7 \%$ finished primary school, 52.3\% had a high-school degree, 12.2\%

171 had higher education and $8.3 \%$ had other type of education. About $60.4 \%$ reported having an

172 occupation. Most of the participants were single $(76.3 \%)$ and lived in their own accommodation

173 (74.6\%) and only a few of them reported living in an institution for individuals with mental illness

174 (16.4\%). Fifteen participants out of the 287 respondents did not answer one or more of the five

175 items in the Satisfaction with Life Scale. Since the missing data was $\leq 5 \%$, we found it appropriate

176 to use the listwise deletion method to handle the missing data. This method excludes respondents

177 with missing scores on any variable or variables used in subsequent analyses. Thus, we ended up 
178 with a sample of 264 participants (age mean $=43.46, S D=13.31$, ranging from 17 to 74 years of

179 age) for the present study (see Figure 1).

180

Figure 1 about here

181

182

183

184

185

186

187

188

189

190

191

192

193

194

195

196

197

198

199

200

\section{Instrument}

The Satisfaction with Life Scale (Diener, Emmons, Larsen \& Griffin, 1985) assesses the cognitive component of subjective well-being and consists of 5 items (i.e., "In most ways my life is close to my ideal", "The conditions of my life are excellent", "I am satisfied with my life", "So far I have gotten the important things I want in life", and "If I could live my life over, I would change almost nothing") that require a response on a 7-point Likert scale (1 = "strongly disagree", 7 = "strongly agree"). The Swedish version of the Satisfaction with Scale (see Table 1) has been used in several studies in the Swedish normal population (e.g., Garcia \& Siddiqui, 2009ab). The sum of the five items is expected to measure life satisfaction as a single factor.

\section{Statistical Procedure}

Firstly, a Pearson correlations analyses was conducted to investigate the relationship between the five items of the Satisfaction with Life Scale. Secondly, we applied an exploratory factor analysis using principal components analysis in SPSS (version 24) to investigate if the items in the Swedish version of the Satisfaction with Life Scale loaded as one single factor, as suggested by previous research in other populations, in our sample of individuals with mental illness. Since there was only one latent factor, namely life satisfaction, we did not use any rotation method. Next, we conducted a confirmatory factor analysis using Structural Equation Modeling (SEM) in AMOS (version 24). In this analysis, we used the Maximum Likelihood estimation method to calculate fit indices and factor loadings. We used multi-group confirmatory factor analysis with three invariance models (i.e., configural, metric, and scalar) in order to test measurement invariance with 
201 regard to gender (females vs. males) and occupation status (employed vs. unemployed) - the only 202 two sociodemographic categories with large enough subsamples for valid and reliable testing (cf. 203 Muthen \& Muthen, 2002; Kline, 2015). Finally, since the items in the Satisfaction with Life Scale 204 are ordinal and scored on a Likert scale, we used Graded Response Model as the IRT technique in 205 the last part of our analyses.

207 Descriptive and Correlational Analysis 
208 The results showed that there were positive and significant relationships among all the items in the

209 scale. See Table 2 for the correlation coefficients, mean values, and standard deviations for all five

210 items of the Swedish version of the Satisfaction with Life Scale.

Table 2 about here

\section{Exploratory Factor Analysis}

213 We found only one latent factor with an eigenvalue higher that 1 (i.e., 3.23; cf. Tabachnick \&

214 Fidell, 2012. See Figure 2). This latent factor explained 64.58\% of the variance in participants'

215 life satisfaction. The loadings for each of the five items on the latent factor (i.e., life satisfaction)

216 were: .88 for item 1 ("In most ways my life is close to my ideal"), .82 for item 2 ("The conditions

217 of my life are excellent"), .88 for item 3 ("I am satisfied with my life"), .79 for item 4 ("So far I

218 have gotten the important things I want in life"), and .63 for item 5 ("If I could live my life over,

219 I would change almost nothing"). Finally, the scale had a Cronbach's $\alpha=.86$ in the present study.

220 In sum, the results were acceptable, consistent with previous research, and suggested that the

221 Satisfaction with Life Scale measures a single factor of life satisfaction in our sample of Swedish

222 individuals with mental illness.

Figure 2 about here

224

225

226

227

228

229

230

\section{Confirmatory Factor Analysis}

The analysis showed that the chi-square value was significant $\left(C h i^{2}=22.57, d f=5, p<.001\right)$. That being said, the chi-square statistic is heavily influenced by sample size, thus, large samples have a higher likelihood of being significant (Kline, 2015). Since the other fit indices suggested a good model (comparative fit index $=.97$, incremental fit index $=.97$, and normed fit index $=.97$ ), we considered that the proposed unidimensional model was acceptable. All regression loadings 
231 between life satisfaction and the five items were significant at $p<.001$ and ranged from .52 to .88

232 (See Figure 3).

233

Figure 3 about here

\section{Measurement Invariance}

235 All the invariance models (i.e., configural, metric, and scalar) indicated no differences in responses

236 to the Satisfaction with Life Scale across gender and occupation groups. More specifically, the

237 difference in comparative fit indexes (CFIs) between the configural and metric model were less

238 than .01. Importantly, since the configural model compares the overall factor structure of the two

239 subsamples in each sociodemographic category group (Lee, 2018), thus, there was no difference

240 in how females and males with mental illness and in how employed and unemployed individuals

241 with mental illness responded to the items in the Satisfaction with Life Scales (Table 3 and 4).

242 Furthermore, the differences between the scalar model (intercepts) against the metric model (factor

243 loadings) were not significant for any of the two sociodemographic categories (Table 3 and 4). In

244 other words, when comparing factor loadings and intercepts, there were no differences in responses

245 to the Satisfaction with Life Scale's items between males and females nor between employed and

246 unemployed within this population of individuals with mental illness. In addition, the differences

247 in CFIs between the metric and scalar models were less than .01, which also indicates that there

248 were no differences in responses to the scale with regard to these two sociodemographic categories.

$\underline{\text { Table } 3 \text { and } 4 \text { about here }}$

250 Graded Response Model

251 Regarding item discrimination, the results showed that all items had high discrimination values

252 (Alpha, $\alpha$, from 1.95 to 3.81). The only exception was item 5 ("If I could live my life over, I would

253 change almost nothing"), which had moderate discrimination values (1.17). Items 1 to 4 showed a 
254 steeper slope, indicating that these items had good discrimination and can differentiate between

255 persons with high and low levels of the latent score of life satisfaction better than item 5 (see Table

256 5). Regarding item difficulty, we found that item 5 had the highest estimated difficulty parameter

257 (-.66) and that item 4 ("So far I have gotten the important things I want in life") had the lowest

258 estimated difficulty parameter (-1.40). For example, for item 1 ("In most ways my life is close to

259 my ideal"), a person with a score of -.94 has a $50 \%$ chance of answering 1 (strongly disagree)

260 rather than responses $2,3,4,5,6$ or 7 ; a person with a score of -.15 has a $50 \%$ chance of responding

2611 or 2 , rather than $3,4,5,6$ or 7 ; while a person with a score of 2.03 has a $50 \%$ chance of responding

2627 , rather than $1,2,3,4,5$ or 6.

\section{Table 5 about here}

We graphed the item information function for each item to see how much information each item provided and to see at what level of the continuum each item had the most or least information. In other words, the item information function reflects the properties of each item in terms of both its difficulty and discrimination index. Here, item 1 ("In most ways my life is close to my ideal") and item 3 ("I am satisfied with my life") had the two highest discrimination estimates and provided more information than any of the remaining items (see Figure 4). Finally, the test information function for the whole scale investigated how reliable the Satisfaction with Life Scale was. As shown in Figure 5, the five items together provided information ranging between -1.00 and 2.00 to measure life satisfaction in our sample of Swedish individuals with mental illness. Thus, the scale had good reliability and a small standard error within this range. The highest amount of information and smallest standard error was at Theta $=0.00$. However, increases for both smaller and larger Theta values. 


\section{Discussion}

279 The current study examined, using both CTT and IRT, the psychometric properties of the 280 Satisfaction with Life Scale in a Swedish sample of individuals with mental illness. Aligned with 281 studies among other populations, our results supported the unidimensional structure of the 282 Satisfaction with Life Scale (e.g., Neto, 1993; Oishi, 2006; Sachs, 2003) and the positive and 283 significant relationships between the five items in the scale. More specifically, the scale had good 284 reliability and best goodness of fit referring to a one single factor with significant loadings between 285 the scale and items ranging from .52 to .88. Moreover, the scale measured life satisfaction across 286 gender and occupational status in the same manner. This is also in line with findings among 287 females and males in Croatian (Brdar et al., 2011) and Swedish samples (Hultell \& Gustavsson, 288 2007). Our findings, however, add a new dimension by establishing that the scale measures life 289 satisfaction equally among individuals with mental illness with and without occupation. This is 290 important, since the ability and possibility of having an occupation varies largely in this population 291 (Granjard et al., 2021).

292 The IRT analyses showed that the items had high discrimination values. The only exception 293 was item 5 ("If I could live my life over, I would change almost nothing."), which had moderate 294 discrimination value and the highest estimated difficulty on response 7. In contrast, item 4 ("So 295 far I have gotten the important things I want in life.") had the lowest estimated difficulty on 296 response 1. Item 2 (“The conditions of my life are excellent") had less discrimination and 297 redundant difficulty with both item 1 ("In most ways my life is close to my ideal.”) on response 7 298 and with item 3 ("I am satisfied with my life.") on response 1. Using item information function 299 curves, we found that items 1 ("In most ways my life is close to my ideal.") and 3 ("I am satisfied 
300 with my life.") had the highest discrimination estimates and provided more information than the

301 other items, while item 5 provided the less. Indeed, the few IRT studies conducted among general

302 populations in China (Oishi, 2006) and the US (Nima et al., 2020b) have also shown that item 5

303 had the lowest discrimination estimate among all five items. As accurately pointed out by Pavot

304 and Diener (2008), item 5 represents an evaluation over one's past life, thus, it probably requires

305 respondents to make more of a global recollection compared to, for example, item 1 (e.g., "In most

306 ways my life is close to my ideal"), which rather requires the apprehension of one's present life.

307 Nevertheless, as accurately suggested by Jovanovic and colleagues (2020), individuals with mental

308 illness have memory issues regarding the past (e.g., negativity bias), thus, such item-related

309 temporal problems need to be scrutinized using IRT among populations with mental illness.

310 Nevertheless, these five items together provided good information, with especial good

311 reliability and small standard error within -1.00 up to about 2.00 and the highest amount of test

312 information at 0.00 of the level of life satisfaction within this population of individuals with mental

313 illness. Moreover, comparative fit index, incremental fit index, and normed fit index were equal

314 to .97 suggesting a good model fit for the Satisfaction with Life Scale among Swedish individuals

315 with mental illness. These findings are also consistent with one study conducted in Iran among

316 psychiatric outpatients. Indeed, the Persian version of the Satisfaction with Life Scale had

317 acceptable internal consistency $(a=.75)$, test-retest reliability $(\mathrm{ICC}=.64)$, comparative fit index

318 (.91), and root mean square error of approximation (.05; Fallahi \& Pasandideh, 2016). In

319 accordance, the validation of the Dutch version of the Satisfaction with Life Scale among a sample

320 of psychiatric patients with severe mental illness also indicated acceptable loadings ( $>.40)$, good

321 internal consistency $(a=.80)$, and fairly well corrected item-total correlations ranging from +.40

322 to +.70 (Arrindell et al., 2001). Finally, the Malaysian version of the Satisfaction with Life Scale 
323 among psychiatric and medical outpatients also showed very high goodness of fit indices (Chi-

324 square $/ \mathrm{df}=1.108 ; \mathrm{GFI}=.993 ; \mathrm{CFI}=.999 ; \mathrm{RMSEA}=.019)$ (Aishvarya et al., 2014). In sum, our

325 results using CTT in a Swedish population of individuals with mental illness, replicate results

326 showing that the Satisfaction with Life Scale has good validity and reliability among psychiatric

327 patients in different cultures. Last but not the least, our IRT results are an important new addition

328 to the scale's validity at the item level in this specific population.

329 Limitations and suggestions for future research

330 Since our sample was relatively small we were not able to investigate measurement invariance

331 within the group across sociodemographic factors, such as, type of psychiatric pathologies (cf.

332 Boncori, De Coro, Cuomo \& Lucchese, 2011), age, marital status, and education. After all, we

333 needed about 100-150 participants per group in order to conduct such analyses (Muthen \& Muthen,

334 2002; Kline, 2015). We recommend that future studies compare life satisfaction as measured by

335 the Satisfaction with Life Scale among individuals with mental illness and individuals without

336 mental illness from the general Swedish population. This will help us to understand whether the

337 Satisfaction with Life Scale is invariant among these two distinct populations. Another major

338 limitation was that we were not able to have access in detail to all different diagnosis in this

339 population. Mental illness is after all a wide concept (Vingård, 2020). As stated earlier, the answers

340 to the items in the Satisfaction with Life Scale could differ between patients with different mental

341 disorders. In addition, the lack of details regarding diagnosis might give the sense of a

342 homogeneous group of individuals, which this population certainly is not.

343 Moreover, despite the fact that the Satisfaction with Life Scale is one of the most prominent

344 and commonly used instruments to measure life satisfaction, there are other instruments that can

345 be used in this endeavor. For example, the Life Satisfaction Questionnaire was originally 
346 developed as a checklist (Fugl-Meyer, Bränholm \& Fugl-Meyer, 1991) targeting important life

347 domains (e.g., vocational, financial, leisure activities, friendships, sexual life, self-care, family,

348 partner relationships) and both physical and psychological health (Melin, Fugl-Meyer \& Fugl-

349 Meyer, 2003). Finally, since life satisfaction might be affected by mood, which can be of great

350 variation in some mental-illnesses, it is plausible to suggest that future studies need to address the

351 test-retest reliability of the Satisfaction with Life Scale in this population and to conduct

352 longitudinal studies. That being said, the IRT analyses conducted in this study regarding reliable

353 item information are not influenced by the characteristic of the sample (Oishi, 2007; Kijima,

354 Takahashi, Noguchi \& Wantaanbe, 1998). Hence, since the main idea behind IRT is that we can

355 measure the latent trait, in this case life satisfaction, we should expect that analyses of test-retest

356 reliability should yield the same results as here.

357 Conclusion and last remarks

358 The psychometric characteristics of the Satisfaction with Life Scale in this sample of Swedish 359 psychiatric patients was acceptable and consistent with previous research suggesting that its five 360 items measure a single factor of life satisfaction. Items 1 ("In most ways my life is close to my 361 ideal") and 3 ("I am satisfied with my life") had the two highest discrimination estimates and 362 provided more information than any of the remaining items. That being said, while the Satisfaction

363 with Life Scale had good information and reliability across most of the latent trait range, it could

364 not measure extreme levels of life satisfaction in our sample of Swedish individuals with mental

365 illness. Thus, some modification might be warranted. For instance, item 5 ("If I could live my life

366 over, I would change almost nothing") had low information value and item 2 ("The conditions of

367 my life are excellent") seems to have redundant difficulty. 
369 satisfaction might be its own construct, but that it also is part of a general subjective well-being

370 factor. In other words, subjective well-being consists of, besides life satisfaction as a cognitive

371 component, an affective component (i.e., positive and negative affect) and a behavioral component

372 (i.e., harmony in life). These three components are in direct connection to each other and are

373 therefore needed to understand people's subjective well-being. Thus, only assessing life

374 satisfaction, give us an incomplete picture of how people are actually feeling about their life and

375 an even smaller insight in their well-being as a whole.

376 That being said, IRT analyses might help clinicians to understand patients' behavior in

377 relation to the patient's responses to the items in the test. For example, while some patients are

378 low in their life satisfaction, they might respond with high levels to a specific item in the test. This

379 specific item might, in turn, give important cues for intervention (Pires, Filgueiras, Ribas \&

380 Santana, 2013). This might be essential; after all, in order to address mental illness in the $21^{\text {st }}$

381 century, we need to develop methods for the prevention, identification and treatment of mental

382 illness; but also, develop methods for the promotion, identification, and maintenance of well-being

383 (see for example Cloninger, Granjard, Lester, Lindskär, Rosenberg, Cloninger \& Garcia, 2021;

384 Garnjard, Cloninger, Lindskär, Jacobsson, Sikström, Cloninger \& Garcia, 2021).

\section{References}

Aishvarya, S., Maniam, T., Karuthan, C., Sidi, H., Jaafar, N. R. N., \& Oei, T. P. S. (2014). Psychometric properties and validation of the Satisfaction with Life Scale in psychiatric and medical outpatients in Malaysia. Comprehensive Psychiatry, 55, S101-S106. 
389 Arrindell, W. A., Meeuwesen, L \& Huyse, F. J. (1991). The Satisfaction with Life Scale (SWLS):

390 Psychometric Properties in a Non-Psychiatric Medical Outpatients Sample. Personality

$391 \quad$ and Individual Differences, 12, 117-123.

392 Arrindell, W. A., van Nieuwenhuizen, C., \& Luteijn, F. (2001). Chronic psychiatric status and 393 satisfaction with life. Personality and individual differences, 31(2), 145-155.

394 Boncori, L., De Coro, A., Cuomo, G., Lucchese, F. (2011). Innovation in psychopathological 395 testing: TALEIA. Part I: Content validity and validity scales. Giornale Italiano di Psicologia, 3, 649-670.

Brdar, I., Anić, P., \& Rijavec, M. (2011). Character strengths and well-being: are there gender differences?. In The human pursuit of well-being (pp. 145-156). Springer, Dordrecht. https://doi.org/10.1007/978-94-007-1375-8 13

Chinni, M. L., \& Hubley, A. M. (2014). A research synthesis of validation practices used to 401 evaluate the Satisfaction with Life Scale (SWLS). In B. D. Zumbo, \& E. K. H. Chan (Eds.), Social indicators research series: Vol. 54. Validity and validation in social, behavioral, and health sciences (pp. 35-66). Cham, Switzerland: Springer International Publishing. https://doi.org/10.1007/978-3-319-07794-9_4.

Cloninger, K. M., Granjard, A., Lester, N., Lindskär, E., Rosenberg, P., Cloninger, C. R., \& Garcia, D. (2021). A Randomized Controlled Pilot Study using Mind-Body Interventions among Refugees in Sweden. International Journal of Person Centered Medicine.

Diener, E. (1984). Subjective well-being. Psychological Bulletin, 95, 542-575. index. American Psychologist, 55, 34-43. 
411 Diener, E., Emmons, R. A., Larsen, R. J., \& Griffin, S. (1985). The satisfaction with life scale. $412 \quad$ Journal of Personality Assessment, 49, 71-75.

413 Diener, E., Lucas, R.E., \& Oishi, S. (2018). Advances and open questions in the science of 414 subjective well-being. Collabra. Psychology, 4(1):15 DOI 10.1525/collabra.115.

415 Diener, E., Wirtz, D., Tov, W., Kim-Prieto, C., Choi, D., Oishi, S., \& Biswas-Diener, R. (2010). New well-being measures: short scales to assess flourishing and positive and negative feelings. Social Indicators Research, 97(2):143-156 DOI 10.1007/s11205-009-9493-y.

Emerson, S. D., Guhn, M., \& Gadermann, A. M. (2017). Measurement invariance of the Satisfaction with Life Scale: Reviewing three decades of research. Quality of Life Research, 26, 2251-2264. https://doi.org/ 10.1007/s11136-017-1552-2.

421

422

423

Fallahi Khesht Masjedi, M., \& Pasandideh, M. M. (2016). Psychometric properties of satisfaction with life scale in psychiatric patients. Iranian Journal of Psychiatry and Clinical Psychology, 22(2), 147-158.

Fugl-Meyer, A., Bränholm, I-B., Fugl-Meyer, K. (1991). Happiness and Domain-Specific Life Satisfaction in Adult Northern Swedes. Clinical Rehabilitations, 5, 25-33.

Garcia, D., Nima, A. A., Granjard, A., \& Cloninger, K. M. (2021). Bring Balance to the Force! A Biopsychosocial Model of Subjective Well-Being: Affectivity, Life Satisfaction, and Harmony in Life. International Journal of Person Centered Medicine.

Garcia, D., \& Siddiqui, A. (2009a). Adolescents' Affective Temperaments: Life Satisfaction, Interpretation and Memory of events. The Journal of Positive Psychology, 4, 155-167. DOI: $10.1080 / 17439760802399349$.

Garcia, D., \& Siddiqui, A. (2009b). Adolescents' Psychological Well-Being and Memory for Life Events: Influences on Life Satisfaction with Respect to Temperamental Dispositions. Journal of Happiness Studies, 10, 387-503. DOI: 10.1007/s10902-008-9096-3. 
435 Gigantesco, A., Fagnani, C., Toccaceli, V., Stazi, M. A., Lucidi, F., Violani, C., \& Picardi, A. 436 (2019). The Relationship Between Satisfaction With Life and Depression Symptoms by Gender. Frontiers in Psychiatry, 10:419. DOI: 10.3389/fpsyt.2019.00419.

438

439

440

441

442

444

445

446

447

448

449

450

451

452

453

454

455

456

457

Granjard, A., Mihailovic, M., Amato, A., Kazemitabar, M., Lucchese, F., Jacobsson, C., Kijima, N., \& Garcia, D. (2021). Occupation and Life Satisfaction among Individuals with Mental Illness: The Mediation Role of Self-Reported Psychophysiological Health. PeerJ, 9:e10829. DOI: 10.7717/peerj.10829.

Granjard, A., Cloninger, K. M., Lindskär, E., Jacobsson, C., Sikström, S., Cloninger, C. R., \& Garcia, D. (2021). Personality Profiles in a Sample of Swedish Long-Term Unemployed. International Journal of Person Centered Medicine.

Hultell, D., \& Gustavsson, J. P. (2008). A psychometric evaluation of the Satisfaction with Life Scale in a Swedish nationwide sample of university students. Personality and Individual Differences, 44(5), 1070-1079. https://doi.org/10.1016/j.paid.2007.10.030

Jovanovic, V., Lazic, M., \& Gavrilov-Jerkovic, V. (2020). Measuring life satisfaction among psychiatric patients: Measurement invariance and validity of the Satisfaction with Life Scale. Clinical Psychology and Psychotherapy, 27, 378-383.

Kijima, N., Takahashi, K., Noguchi, H., \& Wataanbe, N. (1998). The Relationship between Personality Scale and Organizational Socialization Scales: Using Temperament and Character Inventory (TCI). Japanese Association of Administrative Science, 12, 31-48.

Kline, R. B. (2015). Principles and practice of structural equation modeling. Fourth edition. New York: Guilford Press.

Lee, S. T. (2018). Testing for Measurement Invariance: Does your measure mean the same thing for different participants? APS Observer, 31(8). 
458 Marwaha, S., Johnson, S., Bebbington, P. E., Angermeyer, M. C., Brugha, T. S., Azorin, J. M., Kilian, R., Hansen, K., \& Toumi, M. (2007). Rates and correlates of employment in people

460

461 with schizophrenia in the UK, France and Germany. The British Journal of Psychiatry,

Melin, R., Fugl-Meyer, K., \& Fugl-Meyer, A. (2003). Life Satisfaction in 18-64 Year Old Swedes 463 in Relation to Education, Employment Situation, Health and Physical Activity. Journal of

Meyer, C., Rumpf, H.J., Hapke, U., \& John, U. (2004). Impact of psychiatric disorders in the 466 general population: satisfaction with life and the influence of comorbidity and disorder duration. Social Psychiatry and Psychiatric Epidemiology, 39, 435-41. DOI: 10.1007/s00127-004-0755-3.

Muthén, L. K., \& Muthén, B. O. (2002). How to use a Monte Carlo study to decide on sample size and determine power. Structural Equation Modeling, 9(4), 599620. https://doi.org/10.1207/S15328007SEM0904_8.

Neto, F. (1993). The satisfaction with life scale: Psychometrics properties in an adolescent sample. Journal of youth and adolescence, 22(2), 125-134. https://doi.org/10.1007/BF01536648

Nima, A. A., Cloninger, K. M., Lucchese, F., Sikström, S., \& Garcia, D. (2020a). Validation of a general subjective well-being factor using Classical Test Theory. PeerJ 8:e9193. DOI: 10.7717/peerj.9193.

Nima, A. A., Cloninger, K. M., Persson, B. N., Sikström, S., \& Garcia, D. (2020b) Validation of Subjective Well-Being Measures Using Item Response Theory. Frontiers in Psychology, 10:3036. DOI: 10.3389/fpsyg.2019.03036. 
481 Oishi, S. (2006). The concept of life satisfaction across cultures: an IRT analysis. Journal of 482 Research in Personality, 40, 411-423. DOI: 10.1016/j.jrp.2005.02.002.

483 Oishi, S. (2007). The application of structural equation modeling and item response theory to 484 cross-cultural positive psychology research. In A. D. Ong, and M. H. M. van Dulmen 485 (Eds.), Oxford Handbook of Methods in Positive Psychology, (pp. 126-138). New York,

487

488

489

490

491

492

493 NY: Oxford University Press.

Pavot, W. (2018). The cornerstone of research on subjective well-being: Valid assessment methodology. In: Diener, E., Oishi, S., \& Tay, L. (Eds.), Handbook of Well-Being. Noba Scholar Handbook Series: Subjective Well-Being. Salt Lake City, UT: DEF Publishers.

Pavot, W., \& Diener, E. (2008). The satisfaction with life scale and the emerging construct of life satisfaction. The Journal of Positive Psychology, 3(2), 137-152. https://doi.org/10.1080/17439760701756946.

Pavot, W., \& Diener, E. (1993). Review of the Satisfaction With Life Scale. Psychological Assessment, 5, 164-172.

Pavot, W., Diener, E., Colvin, C.R., \& Sandvik, E. (1991). Further validation of the Satisfaction With Life Scale: Evidence for the cross-method convergence of well-being measures. Journal of Personality Assessment, 57, 149-161.

Pires, P., Filgueiras, A., Ribas, R., \& Santana, C. (2013). Positive and Negative Affect Schedule: Psychometric Properties for the Brazilian Portuguese Version. Spanish Journal of Psychology, 16, e58, 1-9. DOI: 10.1017/sjp.2013.60.

Sachs, J. (2003). Validation of the satisfaction with life scale in a sample of Hong Kong university students. Psychologia, 46, 225-234. https://doi.org/10.2117/psysoc.2003.225

Tabachnick, B. G., \& Fidell, L. S. (2012). Using Multivariate Statistics, 6th ed., Pearson, Boston. 
504 Vingård, E. (2020). En kunskapsöversikt - Psykisk ohälsa, arbetsliv och sjukfrånvaro [A

505 Knowledge Overview - Mental Illness, Worklife and Sick Leave]. FORTE: Stockholm.

506 Vittersø, J., Biswas-Diener, R., and Diener, E. (2005). The divergent meanings of life satisfaction:

507 Item response modeling of the satisfaction with life scale in Greenland and Norway. Social

$508 \quad$ Indicators Research, 74, 327-348. doi: 10.1007/s11205-004-4644-7.

509 WHO. (1948). Constitution of the World Health Organization. Retrieved from 510 http://www.who.int/governance/eb/who_constitution_en.pdf.

511 WHO. (2001). Mental Health: new understanding, new hope. Geneva: World Health Organization;

$512 \quad 2001$.

\section{Acknowledgements}

514 We would like to thank the participants and the staff at the five Municipalities in Blekinge for

515 making this research possible. We would also like to thank Ledningssamverkan vård och omsorg

516 (LSVO) in Blekinge for allowing this research. Last but not the least, we want to express our 517 gratitude to Lars-Henry Gustle, Ulrika Harris, and Carina Ström from FoU-avtalet, who designed 518 and conducted the data collection together with other colleagues at the Centre of Competence,

519 Region Blekinge.

\section{Legends and Captions}

521 Table 1. The Swedish version (Garcia \& Siddiqui, 2009ab) of the Satisfaction with Life Scale 522 (Diener, Emmons, Larsen \& Griffin, 1985).

523 Note: The Satisfaction with Life Scale from Diener, E., Emmons, R. A., Larsen, R. J., \& Griffin,

524 S. (1985). The satisfaction with life scale. Journal of Personality Assessment, 49, 71-75.

525 Translation to Swedish by Patricia Rosenberg and Johanna Ekberg. The seven-point Likert scale

526 used is as follows [Swedish translation in brackets]: $1=$ Strongly disagree [Håller verkligen inte 
527 med]; 2 = Disagree [Håller inte med]; $3=$ Slightly disagree [Håller till viss del inte med]; $4=$

528 Neither agree nor disagree [Håller varken med eller inte med]; $5=$ Slightly agree [Håller med till

529 viss del]; $6=$ Agree $[$ Håller med]; 7 = Strongly agree $[$ Håller verkligen med $]$.

530

531 Table 2. Correlations, means and standard deviations ( \pm ) for all five items of the Swedish version

532 of the Satisfaction with Life Scale in a sample of individuals with mental illness.

533 Note: ** $p<.001$; SWLS1: "In most ways my life is close to my ideal", SWLS2: "The conditions

534 of my life are excellent", SWLS3: "I am satisfied with my life", SWLS4: "So far, I have gotten

535 the important things I want in life", SWLS5: "If I could live my life over, I would change almost 536 nothing".

537

538 Table 3. Test of measurement invariance for gender.

540 Table 4. Test of measurement invariance for occupation status.

542 Table 5. Item response analysis of the Swedish version of the Satisfaction with Life Scale in a 543 sample of individuals with mental illness.

544 Note: ${ }^{* *} p<.001$; SWLS1: "In most ways my life is close to my ideal", SWLS2: "The conditions 545 of my life are excellent", SWLS3: "I am satisfied with my life", SWLS4: "So far, I have gotten 546 the important things I want in life", SWLS5: "If I could live my life over, I would change almost 547 nothing". 
549 Figure 1. Recruitment procedure in the present study from the project "Brukarundersökning"

550 (BrUS) conducted at the Center of Competence, Region Blekinge.

551

552 Figure 2. Scree plot for the principal component analysis of the Swedish version of the Satisfaction 553 with Life Scale in a sample of individuals with mental illness.

555 Figure 3. Structural equation model of the Swedish version of the Satisfaction with Life Scale in a 556 sample of individuals with mental illness. Showing all paths from the latent factor to the five items 557 and their standardized parameter estimates.

558 Note: Chi-square $=22.57 ; d f=5 ;$ comparative fit index $=.97$; incremental fit index $=.97$; normed 559 fit index $=.97 . \mathrm{e}=$ error. $N=264$. SWLS1: "In most ways my life is close to my ideal", SWLS2:

560 "The conditions of my life are excellent", SWLS3: "I am satisfied with my life", SWLS4: "So far,

561 I have gotten the important things I want in life", SWLS5: "If I could live my life over, I would 562 change almost nothing".

564 Figure 4. Boundary characteristic curves for the five items of the Swedish version of the 565 Satisfaction with Life Scale in a sample of individuals with mental illness.

566 Note: SWLS1: "In most ways my life is close to my ideal", SWLS2: "The conditions of my life

567 are excellent", SWLS3: "I am satisfied with my life", SWLS4: "So far, I have gotten the important 568 things I want in life", SWLS5: "If I could live my life over, I would change almost nothing". 
570 Figure 5: Items information function graphs for graded response for items in the Swedish version

571 of the Satisfaction with Life Scale (A) and information and standard error graph for graded

572 response (B) for the whole score of the Swedish version of the Satisfaction with Life Scale in a

573 sample of individuals with mental illness.

574 Note: SWLS1: "In most ways my life is close to my ideal", SWLS2: "The conditions of my life

575 are excellent", SWLS3: "I am satisfied with my life", SWLS4: "So far, I have gotten the important

576 things I want in life", SWLS5: "If I could live my life over, I would change almost nothing". 


\section{Table $\mathbf{1}$ (on next page)}

The Swedish version (Garcia \& Siddiqui, 2009ab) of the Satisfaction with Life Scale (Diener, Emmons, Larsen \& Griffin, 1985).

Note: The Satisfaction with Life Scale from Diener, E., Emmons, R. A., Larsen, R. J., \& Griffin,

S. (1985). The satisfaction with life scale. Journal of Personality Assessment, 49, 71-75.

Translation to Swedish by Patricia Rosenberg and Johanna Ekberg. The seven-point Likert scale used is as follows [Swedish translation in brackets]: 1 = Strongly disagree [Håller verkligen inte med]; 2 = Disagree [Håller inte med]; 3 = Slightly disagree [Håller till viss del inte med]; 4 = Neither agree nor disagree [Håller varken med eller inte med]; $5=$ Slightly agree [Håller med till viss del]; $6=$ Agree[Håller med]; $7=$ Strongly agree [Håller verkligen med]. 
1 Table 1. The Swedish version (Garcia \& Siddiqui, 2009ab) of the Satisfaction with Life Scale (Diener, Emmons, Larsen \& Griffin, 2 1985).

\section{English}

Using the 1 - 7 scale below, indicate your agreement with each Använd den sjugradiga skalan nedanför för att ange ditt

Instructions item by placing the appropriate number on the line preceding that förhållningssätt till varje påstående genom att skriva lämplig item. Please be open and honest in your responding.

Item 1 In most ways my life is close to my ideal.

Item 2 The conditions of my life are excellent.

Item 3 I am satisfied with my life.

Item 4 So far, I have gotten the important things I want in life.

Item 5 If I could live my life over, I would change almost nothing.

\section{Swedish}

siffra på raden framför.

I de flesta avseende är mitt liv nära mitt ideal.

Förutsättningarna i mitt liv är utmärkta.

Jag är nöjd med mitt liv.

Än så länge har jag fått de viktiga sakerna i livet jag vill ha.

Om jag kunde leva om mitt liv skulle jag i stort sett inte ändra på något alls.
3

4

Note: The Satisfaction with Life Scale from Diener, E., Emmons, R. A., Larsen, R. J., \& Griffin, S. (1985). The satisfaction with life

scale. Journal of Personality Assessment, 49, 71-75. Translation to Swedish by Patricia Rosenberg and Johanna Ekberg. The seven-

point Likert scale used is as follows [Swedish translation in brackets]: $1=$ Strongly disagree [Håller verkligen inte med]; $2=$ Disagree

[Håller inte med]; 3 = Slightly disagree $[$ Håller till viss del inte med]; $4=$ Neither agree nor disagree $[$ Håller varken med eller inte

med]; $5=$ Slightly agree $[$ Håller med till viss del]; $6=$ Agree $[$ Håller med]; $7=$ Strongly agree $[$ Håller verkligen med $]$. 


\section{Table 2 (on next page)}

Correlations, means and standard deviations ( \pm ) for all five items of the Swedish version of the Satisfaction with Life Scale in a sample of individuals with mental illness.

Note: $* *<.001$; SWLS1: "In most ways my life is close to my ideal", SWLS2: "The conditions of my life are excellent", SWLS3: "I am satisfied with my life", SWLS4: "So far, I have gotten the important things I want in life", SWLS5: "If I could live my life over, I would change almost nothing". 
1 Table 2. Correlations, means and standard deviations ( \pm ) for all five items of the Swedish version 2 of the Satisfaction with Life Scale in a sample of individuals with mental illness.

\begin{tabular}{|c|c|c|c|c|c|}
\hline ITEMS & SWLS1 & SWLS2 & SWLS3 & SWLS4 & SWLS5 \\
\hline SWLS1 & - & & & & \\
\hline SWLS2 & $.72^{* *}$ & _- & & & \\
\hline SWLS3 & $.75^{* *}$ & $.62^{* *}$ & - & & \\
\hline SWLS4 & $.56^{* *}$ & $.55^{* *}$ & $.63^{* *}$ & - & \\
\hline SWLS5 & $.43^{* *}$ & $.37^{* *}$ & $.46^{* *}$ & $.43^{* *}$ & _- \\
\hline Mean and $S D$ & $3.17 \pm 1.78$ & $3.44 \pm 1.80$ & $3.67 \pm 1.80$ & $3.85 \pm 1.90$ & $2.83 \pm 1.91$ \\
\hline \multicolumn{6}{|c|}{$\begin{array}{l}\text { Note: ** } p<.001 \text {; SWLS1: "In most ways my life is close to my ideal", SWLS2: "The conditions } \\
\text { of my life are excellent", SWLS3: "I am satisfied with my life", SWLS4: "So far, I have gotten } \\
\text { the important things I want in life", SWLS5: "If I could live my life over, I would change almost }\end{array}$} \\
\hline
\end{tabular}


Table 3 (on next page)

Test of measurement invariance for gender. 
1 Table 3. Test of measurement invariance for gender.

\begin{tabular}{llllll}
\hline Model & Chi-Square & Degrees of Freedom & P-Value & CFI & RMSEA \\
\hline Configural & 32.378 & 10 & .0003 & .965 & .129 \\
Metric & 35.264 & 14 & .0013 & .966 & .106 \\
Scalar & 39.089 & 18 & .0028 & .967 & .094 \\
Models Compared & Chi-Square & Degrees of Freedom & P-Value & \\
Metric vs.. Configural & 2.887 & 4 & .5770 & \\
Scalar vs. Configural & 6.711 & 8 & .5681 & \\
Scalar vs. Metric & 3.825 & 4 & .4302 & & \\
\hline
\end{tabular}

2 
Table 4 (on next page)

Test of measurement invariance for occupation status. 
1 Table 4. Test of measurement invariance for occupation status.

\begin{tabular}{llllll}
\hline Model & Chi-Square & Degrees of Freedom & P-Value & CFI & RMSEA \\
\hline Configural & 37.480 & 10 & .0000 & .957 & .142 \\
Metric & 39.486 & 14 & .0003 & .960 & .116 \\
Scalar & 45.411 & 18 & .0004 & .957 & .106 \\
Models Compared & Chi-Square & Degrees of Freedom & P-Value & \\
Metric against Configural & 2.006 & 4 & .7346 & \\
Scalar against Configural & 7.930 & 8 & .4403 & \\
Scalar against Metric & 5.924 & 4 & .2049 & \\
\hline
\end{tabular}

2

3 


\section{Table 5 (on next page)}

Item response analysis of the Swedish version of the Satisfaction with Life Scale in a sample of individuals with mental illness.

Note: ** $p<.001$; SWLS1: "In most ways my life is close to my ideal", SWLS2: "The conditions of my life are excellent", SWLS3: "I am satisfied with my life", SWLS4: "So far, I have gotten the important things I want in life", SWLS5: "If I could live my life over, I would change almost nothing". 
1 Table 5. Item response analysis of the Swedish version of the Satisfaction with Life Scale in a 2 sample of individuals with mental illness.

\begin{tabular}{|c|c|c|c|c|c|c|c|}
\hline Item & Parameter & Coef. & $S E$ & $\boldsymbol{Z}$ & $\boldsymbol{P}$ & \multicolumn{2}{|c|}{ CI $95 \%$} \\
\hline \multirow{8}{*}{$\frac{\sqrt[n]{3}}{3}$} & Discrimination & 3.81 & 0.50 & 7.70 & 0.00 & 2.84 & 4.79 \\
\hline & Difficulty & & & & & & \\
\hline & $>=2$ & -0.94 & 0.10 & -9.32 & 0.00 & -1.14 & -0.74 \\
\hline & $>=3$ & -0.15 & 0.08 & -1.77 & 0.08 & -0.31 & 0.02 \\
\hline & $>=4$ & 0.25 & 0.08 & 2.91 & 0.00 & 0.08 & 0.41 \\
\hline & $>=5$ & 0.64 & 0.09 & 7.00 & 0.00 & 0.46 & 0.82 \\
\hline & $>=6$ & 1.32 & 0.12 & 11.43 & 0.00 & 1.10 & 1.55 \\
\hline & 7 & 2.03 & 0.18 & 11.43 & 0.00 & 1.68 & 2.38 \\
\hline \multirow{8}{*}{$\sum_{0}^{2}$} & Discrimination & 2.41 & 0.26 & 9.29 & 0.00 & 1.90 & 2.92 \\
\hline & Difficulty & & & & & & \\
\hline & $>=2$ & -1.21 & 0.13 & -9.33 & 0.00 & -1.47 & -0.96 \\
\hline & $>=3$ & -0.29 & 0.09 & -3.05 & 0.00 & -0.47 & -0.10 \\
\hline & $>=4$ & 0.03 & 0.09 & 0.30 & 0.77 & -0.15 & 0.21 \\
\hline & $>=5$ & 0.57 & 0.10 & 5.73 & 0.00 & 0.38 & 0.77 \\
\hline & $>=6$ & 1.30 & 0.13 & 9.82 & 0.00 & 1.04 & 1.57 \\
\hline & 7 & 2.03 & 0.19 & 10.46 & 0.00 & 1.65 & 2.41 \\
\hline \multirow{8}{*}{$\sum_{n}^{\infty}$} & Discrimination & 3.23 & 0.37 & 8.68 & 0.00 & 2.50 & 3.96 \\
\hline & Difficulty & & & & & & \\
\hline & $>=2$ & -1.24 & 0.12 & -10.36 & 0.00 & -1.48 & -1.01 \\
\hline & $>=3$ & -0.52 & 0.09 & -5.83 & 0.00 & -0.70 & -0.35 \\
\hline & $>=4$ & -0.10 & 0.08 & -1.14 & 0.26 & -0.26 & 0.07 \\
\hline & $>=5$ & 0.40 & 0.09 & 4.51 & 0.00 & 0.23 & 0.58 \\
\hline & $>=6$ & 1.00 & 0.11 & 9.39 & 0.00 & 0.79 & 1.21 \\
\hline & 7 & 1.82 & 0.16 & 11.40 & 0.00 & 1.51 & 2.13 \\
\hline \multirow{8}{*}{$\sum_{\infty}^{+}$} & Discrimination & 1.95 & 0.21 & 9.18 & 0.00 & 1.53 & 2.36 \\
\hline & Difficulty & & & & & & \\
\hline & $>=2$ & -1.40 & 0.16 & -8.97 & 0.00 & -1.70 & -1.09 \\
\hline & $>=3$ & -0.65 & 0.11 & -5.82 & 0.00 & -0.87 & -0.43 \\
\hline & $>=4$ & -0.17 & 0.10 & -1.73 & 0.08 & -0.37 & 0.02 \\
\hline & $>=5$ & 0.21 & 0.10 & 2.07 & 0.04 & 0.01 & 0.41 \\
\hline & $>=6$ & 0.94 & 0.13 & 7.47 & 0.00 & 0.69 & 1.18 \\
\hline & 7 & 1.85 & 0.19 & 9.76 & 0.00 & 1.48 & 2.22 \\
\hline \multirow{8}{*}{$\sum_{0}^{n}$} & Discrimination & 1.17 & 0.16 & 7.37 & 0.00 & 0.86 & 1.48 \\
\hline & Difficulty & & & & & & \\
\hline & $>=2$ & -0.66 & 0.15 & -4.24 & 0.00 & -0.96 & -0.35 \\
\hline & $>=3$ & 0.36 & 0.14 & 2.65 & 0.01 & 0.09 & 0.63 \\
\hline & $>=4$ & 0.73 & 0.15 & 4.75 & 0.00 & 0.43 & 1.02 \\
\hline & $>=5$ & 1.34 & 0.20 & 6.76 & 0.00 & 0.95 & 1.72 \\
\hline & $>=6$ & 2.07 & 0.27 & 7.58 & 0.00 & 1.53 & 2.60 \\
\hline & 7 & 3.06 & 0.41 & 7.38 & 0.00 & 2.25 & 3.87 \\
\hline
\end{tabular}

3 Note: $* * p<.001$; SWLS1: "In most ways my life is close to my ideal", SWLS2: "The conditions

4 of my life are excellent", SWLS3: "I am satisfied with my life", SWLS4: "So far, I have gotten 
5 the important things I want in life", SWLS5: "If I could live my life over, I would change almost 6 nothing".

7 
Figure 1

Recruitment procedure in the present study from the project "Brukarundersökning" (BrUS) conducted at the Center of Competence, Region Blekinge. 
Individuals receiving

support from the municipalities in Blekinge at the time of the study $N=621$
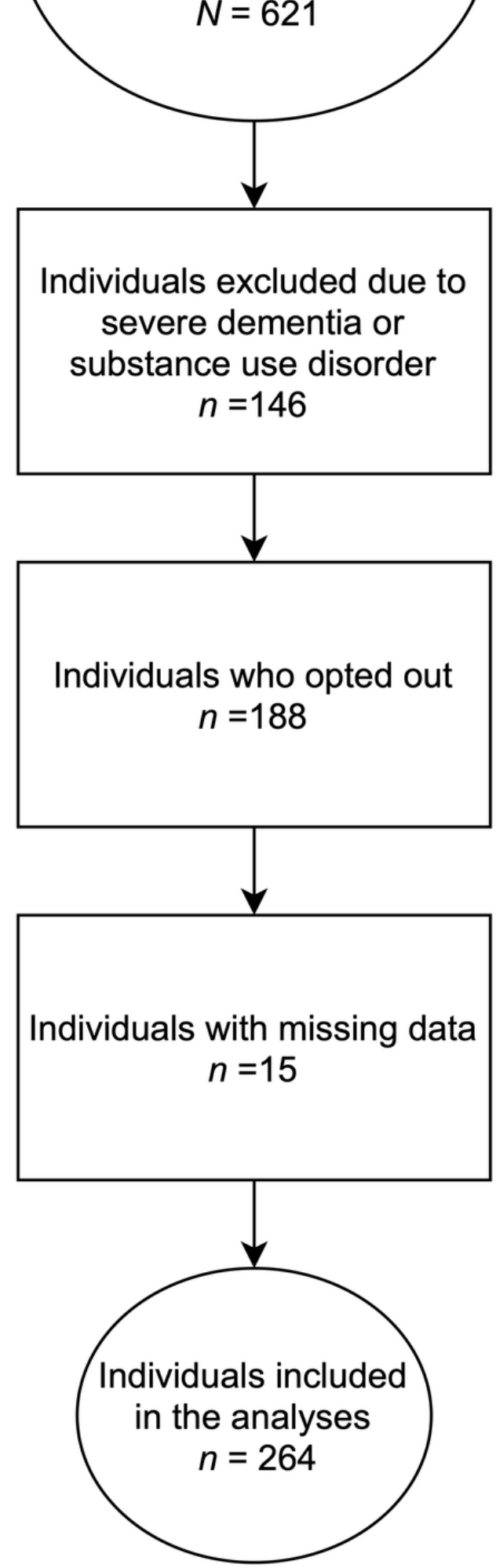
Figure 2

Scree plot for the principal component analysis of the Swedish version of the Satisfaction with Life Scale in a sample of individuals with mental illness.

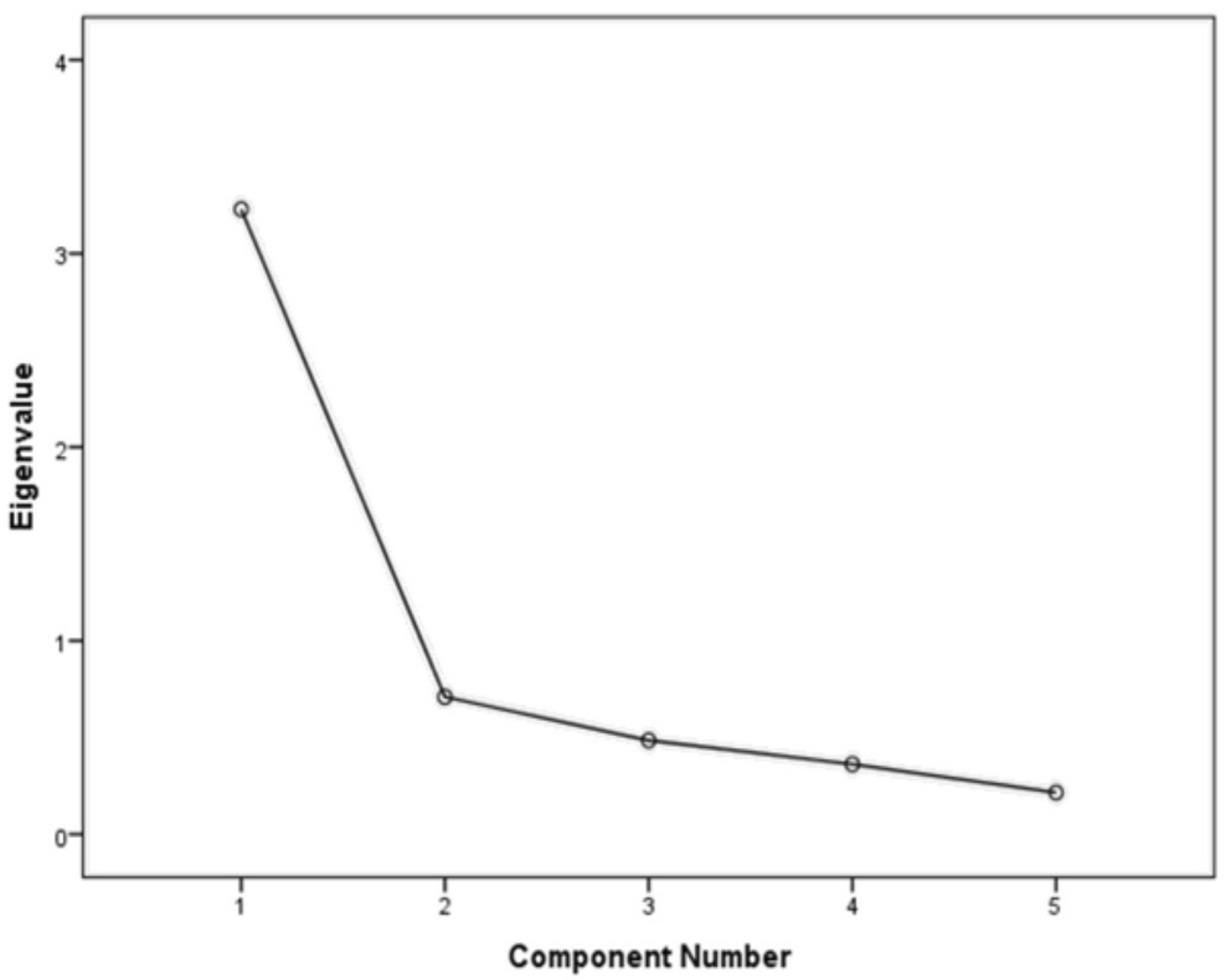




\section{Figure 3}

Structural equation model of the Swedish version of the Satisfaction with Life Scale in a sample of individuals with mental illness. Showing all paths from the latent factor to the five items and their standardized parameter estimates.

Note: Chi-square $=22.57 ; d f=5 ;$ comparative fit index $=.97$; incremental fit index $=.97$; normed fit index $=.97 . \mathrm{e}=$ error. $N=264$. SWLS1: "In most ways my life is close to my ideal", SWLS2: "The conditions of my life are excellent", SWLS3: "I am satisfied with my life", SWLS4: "So far, I have gotten the important things I want in life", SWLS5: "If I could live my life over, I would change almost nothing". 


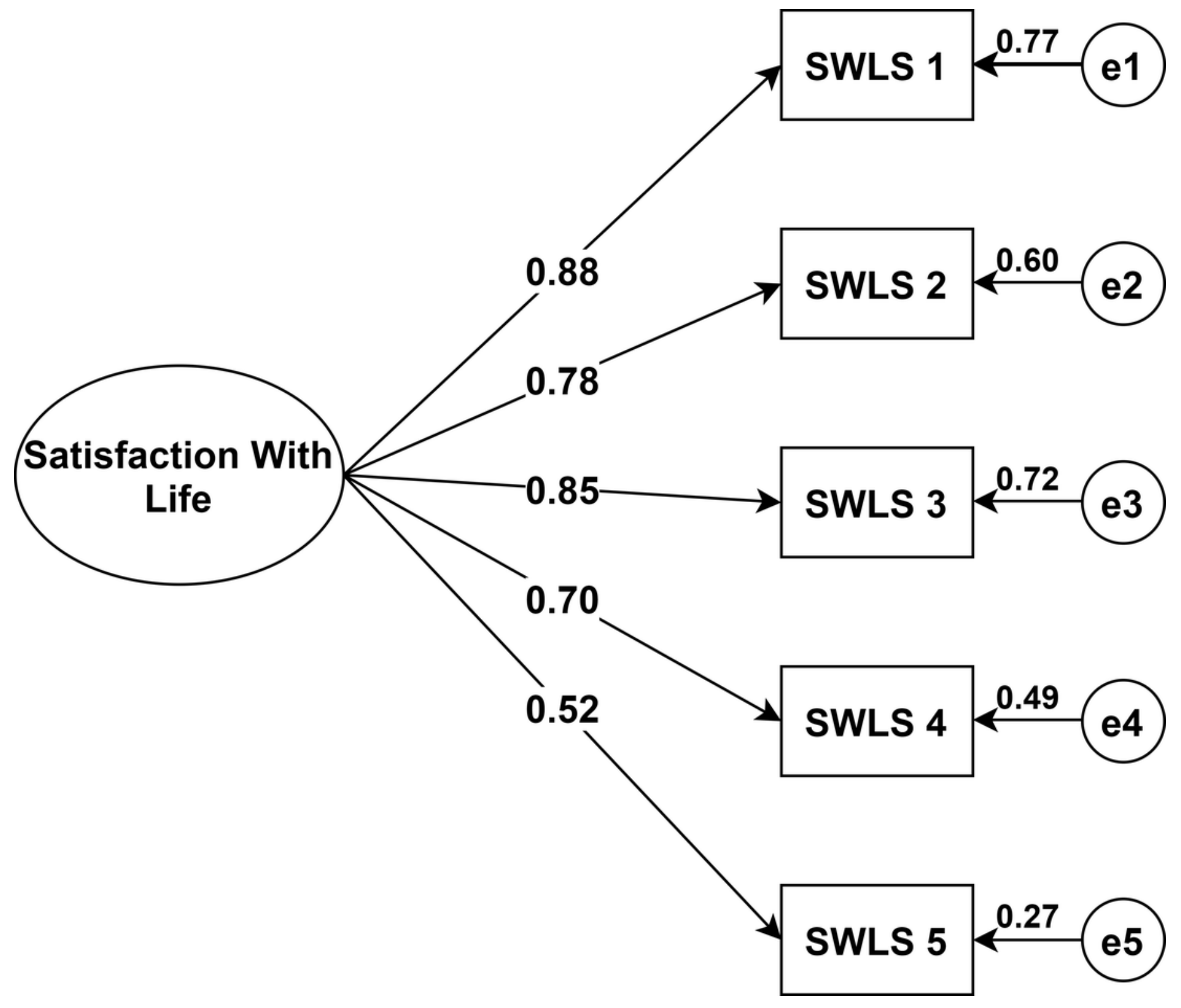


Figure 4

Boundary characteristic curves for the five items of the Swedish version of the Satisfaction with Life Scale in a sample of individuals with mental illness.

Note: SWLS1: "In most ways my life is close to my ideal", SWLS2: "The conditions of my life are excellent", SWLS3: "I am satisfied with my life", SWLS4: "So far, I have gotten the important things I want in life", SWLS5: "If I could live my life over, I would change almost nothing". 

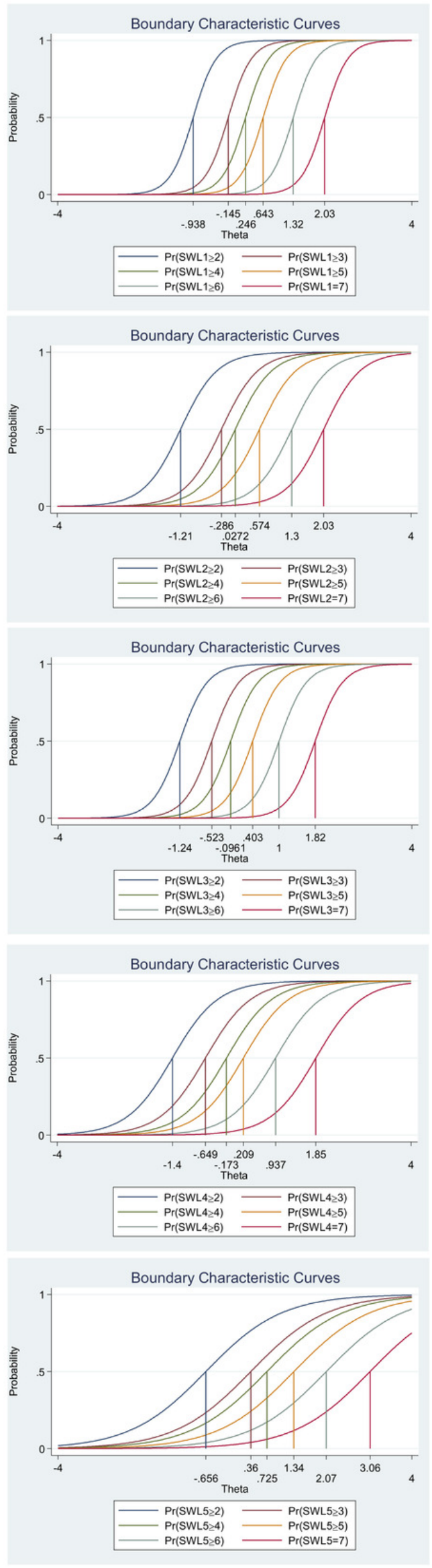

Peer) reviewing PDF | (2021:01:57362:1:0:NEW 26 Mar 2021) 


\section{Figure 5}

Items information function graphs for graded response for items in the Swedish version of the Satisfaction with Life Scale (A) and information and standard error graph for graded response (B) for the whole score of the Swedish version of the Satisfaction

Note: SWLS1: "In most ways my life is close to my ideal", SWLS2: "The conditions of my life are excellent", SWLS3: "I am satisfied with my life", SWLS4: "So far, I have gotten the important things I want in life", SWLS5: "If I could live my life over, I would change almost nothing". 


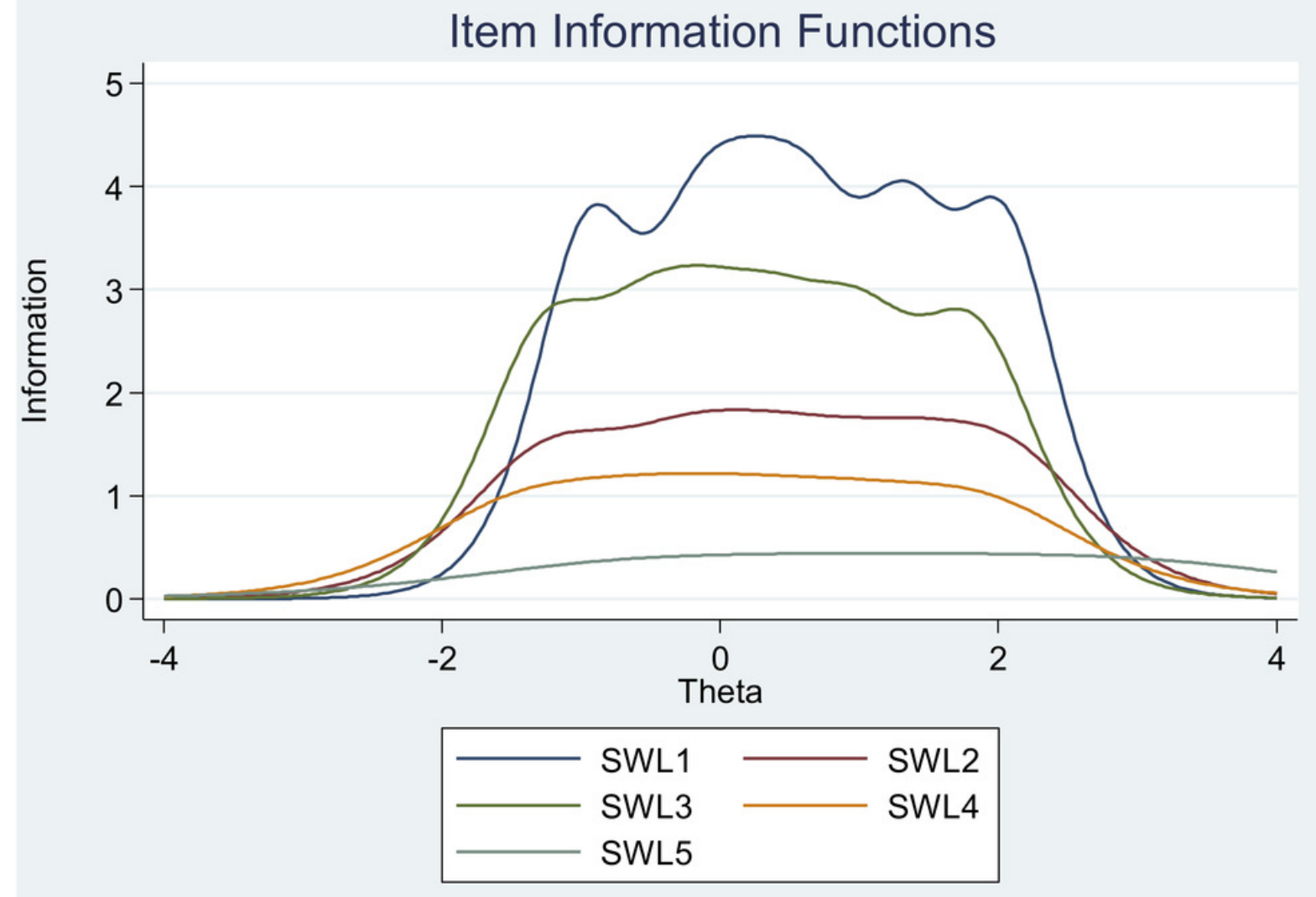

A

\section{Test Information Function}

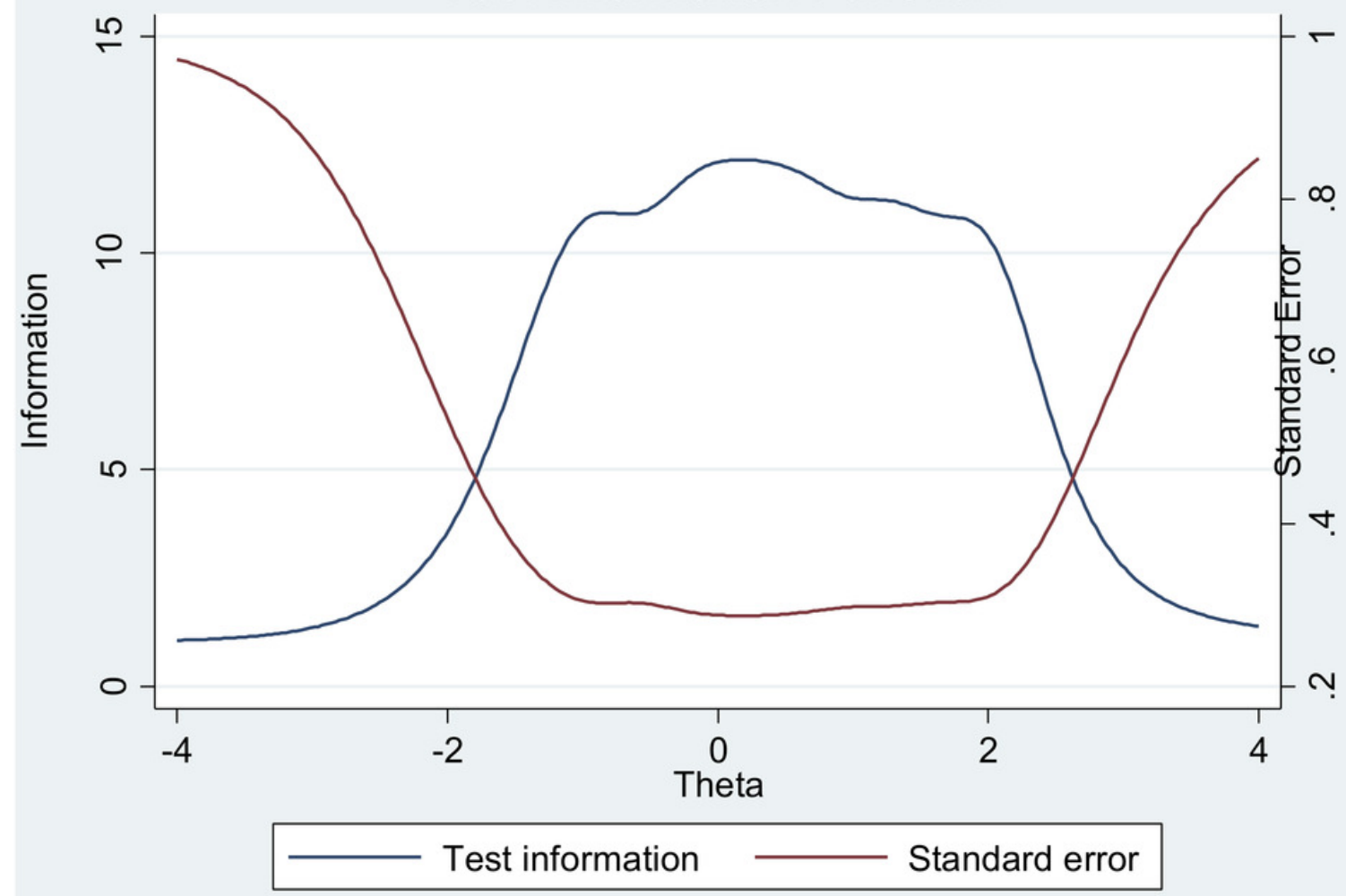

B 